\title{
В.П. Леонов
}

\section{История книжной культуры как фундаментальная проблема библиотековедения}

Реферат. Рецензируемая монография Ю.Н. Столярова «Истоки книжной культуры» - уникальное отечественное исследование мифов, фольклора, религиозных верований, эпоса, в котором каждому из истоков посвящена отдельная глава. Автор ставит задачу реструктурировать отечественную традицию книжной культуры и прослеживает эволюцию истоков с позиций современного книговедения. В эволюции мифов, фольклора, верований, эпоса просматривается познанная объективность мира, даже предугаданное в нем. Это сделано впервые, в чем одна из главных заслуг автора. Ю.Н. Столяров опирается на множество оригинальных работ прошлого и настоящего, исследователей отечественных и зарубежных текстов. Это делает книгу богато насыщенной научно-исследовательским и справочным материалом, представленным конкретными временами и именами. Монография убеждает читателя, что автор формулирует свою концепцию знания о книжной культуре и предлагает библиотечным специалистам перейти на новый уровень ее изучения и понимания. Описывая роль и место книги, Ю.Н. Столяров показывает ее как носителя коммуникации с древнейшего времени. Особо интересны его наблюдения о зарождении истоков реферирования. Чтение книги приводит к выводу, что человеку присущ инстинкт культуры. В ее движении и развитии заключен смысл человеческой деятельности. В процессе эволюции это движение превращается в арену состязания. Мир книжной культуры перестает быть универсальным, он становится порождением ее многообразия. Монография прекрасно издана, снабжена аннотированным именным указателем, подробным библиографическим списком использованной литературы. Книгу Ю.Н. Столярова нужно рассматривать как стартовую площадку для изучения глубинных основ книжной культуры каждого народа.

Ключевые слова: Ю.Н. Столяров, книжная культура, истоки, письменность, книга, библиотековедение, книговедение, библиография, библиотечные специалисты.

Для цитирования: Леонов В.П. История книжной культуры как фундаментальная проблема библиотековедения // Библиотековедение. 2018. Т. 67, № 3. C. 287-290. DOI: 10.25281/0869-608X-201867-3-287-290.

$\mathrm{M}$ онографию Ю.Н. Столярова «Истоки книжной культуры» [1] с полным основанием можно оценить как уникальное издание, не имеющее прямых аналогов в отечественной науке. Перед нами - описание истоков книжной культуры, впервые собранных вместе из различных мифов, фольклора, религиозных верований, эпоса. Проведенный автором анализ каждого истока являет собой хрестоматийные образцы с обширным справочным материалом. Попытаюсь дать некоторое представление об этой богатейшей по информационной насыщенности фактами книге, именно некоторое, так как любое изложение ее содержания будет неполным.

Юрий Николаевич Столяров хорошо известен библиотечному сообществу: главный научный сотрудник Научного центра исследований книжной культуры РАН, доктор педагогических наук, профессор, заслуженный работник высшей школы Российской Федерации, почетный про-

\author{
Валерий Павлович \\ Леонов, \\ Библиотека Российской академии наук, \\ научный руководитель \\ Биржевая линия, д. 1, \\ Санкт-Петербург, 199034, Россия \\ доктор педагогических наук, профессор \\ E-mail: valleo@mail.ru
}

фессор Челябинского государственного института культуры. Он принадлежит к числу ученых-исследователей, которые находятся в постоянном поиске, составляют гордость и славу нашей науки. Юрий Николаевич внес большой вклад в развитие библиотечного образования, подготовив ряд учебников для институтов культуры. Среди его замечательных книг выделю лишь некоторые: «Библиотечный фонд» (2015), «Документология» 
(2013); «Защита библиотечного фонда» (2006); «Библиотековедение, библиографоведение и книговедение как единая научная специальность" (2007); «Сущность информации» (2000).

Проблемы, поставленные и обстоятельно обсуждаемые в данной монографии (автор работал над ней 20 лет!), предельно масштабны, своевременны и значимы не только для библиотековедения, библиографоведения и книговедения в их современном понимании и дальнейшем развитии, но и для преподавания указанных дисциплин - важнейшего направления обучения будущих библиотечных специалистов. Юрий Николаевич поставил задачу раскрыть предысторию и механизмы формирования книжной культуры как процесса особого - творческого. Он описывает мир созданных человеком ценностей как культурный феномен, в котором есть не только действительное, но и «чудесное».

Обосновывая свою позицию во введении, автор в последующих главах показывает не только комплекс обсуждаемых сегодня вопросов, составляющих статус наук о книге. В этом контексте осмысливаются и разворачиваются предшествующие

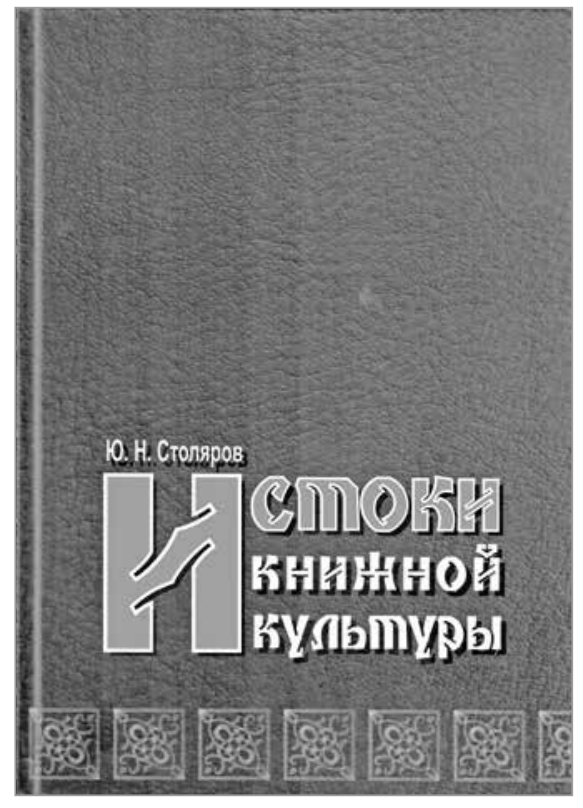

Обложка издания знания о книжной культуре, тем самым предлагая современным библиотечным специалистам перейти на новый уровень ее изучения и понимания. Например, описывая роль и место книги, он показывает ее как носителя коммуникации, начиная с древнейших времен [1, с. 248-251]. Очень интересно наблюдение автора о зарождении истоков реферирования [1, с. $251-253]$. Для их развития потребовался долгий исторический опыт передачи знания.

Чтение этой книги логично приводит к выводу, что человеку присущ инстинкт культуры, иначе говоря - стремление к культуре, ее созданию. Это и есть то, что мы называем «дух». Религия наименовала его словом «бог». Движение культуры как смысл человеческой деятельности есть не что иное как стремление к бессмертию, без чего невозможна ни сама культура, ни ее творчество. И еще один важный вывод. Исследовательское пространство культуры не может быть ничейным, в процессе эволюции оно превращается в арену состязания. Мир книжной культуры не является и универсальным. Он становится порождением ее многообразия.

В заключение коснусь дискуссионной темы о внеземном ей истоки. Каждому из них посвящена отдельная глава. Объем четырех глав впечатляет. Правда, они неравнозначны по широте и глубине охвата. Описание мифов, богов и героев - изобретателей письма (исток первый) занимает 36 страниц, фольклора (исток второй) - 140, религиозных верований (исток третий) - 153, эпоса (исток четвертый) - 78 страниц. Автор сам осознает разную степень полноты представления истоков, называя это «первым приближением» к изучению предыстории книжной культуры. Но в целостном виде такого описания истоков до него не сделал никто.

Ю.Н. Столяров впервые ставит задачу реструктурировать отечественную традицию книжной культуры и прослеживает эволюцию каждого истока с позиций современного книговедения. В эволюции мифов, фольклора, религиозных верований и эпоса просматривается познанная объективность мира, даже нечто предугаданное в нем. Это сделано также впервые, в чем одна из главных заслуг автора.

Обосновывая свои принципиальные размышления и выводы, ученый опирается на множество работ прошлого и настоящего, отечественных и зарубежных текстов, что делает книгу богато насыщенной научно-исследовательским и справочным материалом, представленным конкретными временами и именами. Прочтение монографии убеждает, что автор формирует во многом новую концепцию происхождении письменности и книге как врожденной программе человека. Юрий Николаевич приводит пространную цитату из моей статьи [2] и подчеркивает в сноске: «Констатирую это мнение как имеющий место быть научный факт. Лично моя (Ю.Н. Столярова. - В. Л.) позиция - вполне материалистическая» [1, с. 23-24].

За время, прошедшее после публикации [2], моя точка зрения не изменилась, повторю свои аргументы.

Во-первых, современный человек появился с речью. Как появилась речь? Это до сих пор никто не знает. Возникла речь, и обучение пошло стремительно, началась небиологическая эволюция. Человек разумный остановил естественный отбор. На первых порах побеждал тот, у кого гены были лучше. А далее победителями становились другие - у кого знания были лучше. Важно заметить, что знание не передается генетическим путем. Поэтому узнать и понять человек должен сам.

Во-вторых, появление письменности как записи речи тоже остается загадкой. Чтобы создать письменность, необходимо было понимать, что она будет представлять собой, какова ее миссия. Письменность создавалась, когда уже было комуто ясно, как и для чего она может служить. Другими словами, уже сформировалось понимание ценности информации, записанной кем-то и сохраненной на длительное время [3] ${ }^{1}$. 
B-третьих, возникновение книги как космического субъекта, как врожденной программы человека предусмотрено природой. Добавлю к сказанному мнение философа В.А. Лефевра, полагавшего, что «сегодня единственные известные нам космические субъекты - это мы сами» [4, с. 19].

Рецензируемая монография Ю.Н. Столярова вдохновлена самыми жизненными запросами современной книжной культуры и, в сущности, отвечает на многие из них. Книга прекрасно издана, снабжена, что очень редко встречается в такого рода изданиях, аннотированным именным указателем, подробным библиографическим списком использованной литературы. Она дает простор для дальнейшего самостоятельного и углубленного исследования каждого истока книжной культуры, что сформирует ее новое научное направление. Поэтому оценить труд Ю.Н. Столярова нужно как стартовую площадку для изучения глубинных основ книжной культуры каждого народа.

\section{Примечание}

1 «Прославление писцов» переведено А. Ахматовой. По мнению И. Кацнельсона, оригинальный текст был написан в Фивах около 1300 г. до н. э.

\section{Список источников}

1. Столяров Ю.Н. Истоки книжной культуры / под ред. В.Я. Рушанина ; отв. за вып. Т.Ф. Берестова ; Челяб. гос. ин-т культуры. Челябинск : ЧГИК, $2017.500 \mathrm{c}$.

2. Леонов В.П. Книга как врожденная программа человека / Книга. Исследования и материалы. 2008. Сб. 88/1. С. 78-79.

3. [Прославление писцов] // Лирика Древнего Египта / пер. с егип.: А. Ахматовой, В. Потаповой ; сост., вступ. ст., примеч. И. Кацнельсона. Москва : Худож. лит., 1965. С. 89-93.

4. Лефевр В.А. Космический субъект. Москва : Инкварто, 1996. $183 \mathrm{c.}$

\title{
History of Book Culture as a Fundamental Problem of Library Science
}

\author{
Valerii P. Leonov, \\ Russian Academy of Sciences Library, 1 Birzhevaya Liniya, St. Petersburg, 199034, Russia \\ E-mail: valleo@mail.ru
}

\begin{abstract}
The reviewed monograph "The Origins of Book Culture" by Y.N. Stolyarov is a unique domestic study of the origins of book culture, such as myths, folklore, religious beliefs, and epos. Each of the origins is considered in a separate chapter of the book. The author sets the task to restructure the domestic tradition of book culture and traces the evolution of the sources from the standpoint of modern book science. In the evolution of myths, folklore, beliefs, and epos one there is seen the cognized objectivity of the world, even the prediction in the future. This is done for the first time and it is one of the main merits of the author. Y.N. Stolyarov relies on many original works of the past and the present of the researchers of Russian and foreign texts. This makes the book rich in research and reference materials, presented by specific times and names. The text of the monograph convinces the reader that the author formulates his own concept of knowledge on the book culture and offers the library professionals to move to a new level of its study and understanding. Describing the role and place of the book, Y.N. Stolyarov shows it as a carrier of communication from ancient times. Of particular interest are his observations about the origins of abstracting. Reading the book leads to conclusion that the instinct of culture is inherent to human. The sense of human activity lies in culture movement and evolution. In the process of evolution, this movement becomes an arena for competition. The world of book culture ceases to be universal; it becomes a product of its diversity. Monograph is beautifully published, has an annotated index and detailed bibliographic list of literature. Y.N. Stolyarov's book should be considered as a launching platform for studying the deep fundamentals of the book culture of every nation and people.
\end{abstract}

Key words: Y.N. Stolyarov, Book Culture, Origins, Writing, Book, Library Science, Book Science, Bibliography, Library Professionals.

Citation: Leonov V.P. History of Book Culture as a Fundamental Problem of Library Science, Bibliotekovedenie [Library and Information Science (Russia)], 2018, vol. 67, no. 3, pp. 287-290. DOI: 10.25281/0869608X-2018-67-3-287-290. 


\section{References}

1. Stolyarov Yu.N. Istoki knizhnoi kul'tury [The Origins of Book Culture]. Chelyabinsk, ChGIK Publ., 2017, 500 p.

2. Leonov V.P. Book as an Innate Human Program, Kniga.Issledovaniya i materialy [Book. Researches and Materials], 2008, coll. 88/1, pp. 78-79 (in Russ.).
3. Katsnelson I. (ed.) Lirika Drevnego Egipta [Lyrics of Ancient Egypt]. Moscow, Khudozhestvennaya Literatura Publ., 1965, pp. 89-93.

4. Lefebvre V.A. Kosmicheskii sub' ekt [The Space Subject]. Moscow, In-kvarto Publ., 1996, 183 p.

Анонс

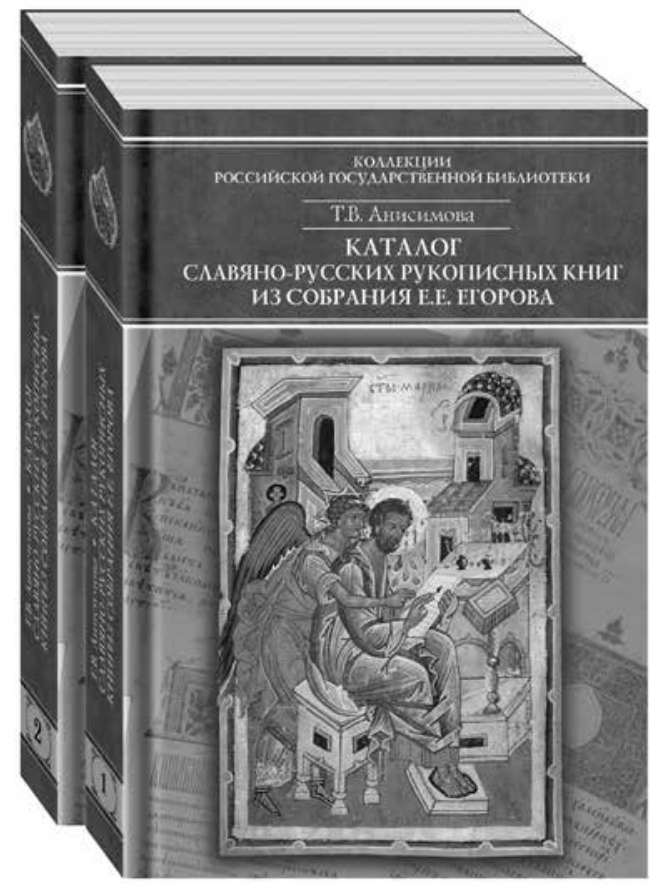

Анисимова Т.В. Каталог славяно-русских рукописных книг из собрания Е.Е. Егорова. Т. 2. № 101-200 / под ред. Ю.С. Белянкина ; Российская гос. б-ка. Москва : Пашков дом, 2018. 336 с. : ил. (Коллекции Российской государственной библиотеки).

Хранящееся в отделе рукописей Российской государственной библиотеки собрание славяно-русских рукописных книг Е.Е. Егорова (ОР РГБ. Ф. 98) - одна из ценнейших в мире частных коллекций. Она насчитывает 2073 ед. хранения, большинство которых датируются от XIV до XVI в. и имеют исключительные художественные достоинства.

Во втором томе каталога собрания Е.Е. Егорова содержатся описания рукописей № 101-200. Одна из них датируется рубежом XIV-XV вв., $14-\mathrm{XV}$ в., $54-\mathrm{XVI}$ веком. По содержанию это житийные сборники, памятники канонического права и святоотеческой литературы, патерики, богослужебные книги (Евангелия тетр и апракос, Апостолы апракос, Минеи, Прологи, Торжественники), толковые произведения (16 Слов Григория Богослова, «Толковые пророчества», Учительное Евангелие), два списка «Христианской топографии» Козьмы Индикоплова (один - лицевой). Историческая литература представлена списком Хронографа Русского (первая четверть XVII в.). Особую ценность представляют Кормчая Нифонта Кормилицына (вторая четверть XVI в.), вкладной синодик боярского сына П.С. Бабина в Никольскую Сретенскую церковь (первая четверть XVII в.), а также два знаменитых оригинальных списка «Поморских ответов выговских пустынножителей на вопросы иеромонаха Неофита" (1723 г.).

География бытования книг достаточно обширна: Москва, Киев, Новгород, Владимир, Вологда, Рязань, Нижний Новгород, российский север (Архангельск, Холмогоры, Вологда, Северная Двина, Ладога) и юг (Астрахань), Афон и Молдавия. Более 30 рукописей имеют монастырское происхождение; многие книги имеют владельческие записи и принадлежали известным историческим лицам, среди которых: царь и великий князь всея Руси Михаил Федорович, боярин Василий Ботвиньев, Антоний, архимандрит Спасо-Преображенского Астраханского монастыря, Кирилл Завидов, архимандрит Троице-Сергиевой Лавры, Амфилохий, архимандрит Угличский, Афанасий, архиепископ Холмогорский и Важеский и др.

Научные описания включают подробную информацию о каждой рукописи: содержании, водяных знаках, художественных особенностях, переплете, записях на книгах, сохранности. Многие описания сопровождаются иллюстрациями. Ряд указателей делает информацию доступной для специалистов широкого профиля.

Одновременно со вторым томом каталога будет выпущено второе дополненное издание первого тома.

Справки и заказ изданий:

119019, Москва, ул. Воздвиженка, 3/5

Российская государственная библиотека, Отдел книжных изданий

+7 (499) 557-04-70, доб. 25-72; Pashkov_Dom.Book@rsl.ru

http://store.rsl.ru/service/pashkov_dom 